This PDF is a selection from a published volume from the National Bureau of Economic Research

Volume Title: Frontiers in Health Policy Research, Volume 5

Volume Author/Editor: Alan M. Garber, editor

Volume Publisher: MIT Press

Volume ISBN: 0-262-07234-3

Volume URL: http://www.nber.org/books/garb02-1

Conference Date: June 7, 2001

Publication Date: January 2002

Title: The Effects of Medicare on Health Care Utilization and Outcomes

Author: Frank R. Lichtenberg

URL: http://www.nber.org/chapters/c9857 


\title{
The Effects of Medicare on Health Care Utilization and Outcomes
}

\author{
Frank R. Lichtenberg, Columbia University and NBER
}

\section{Executive Summary}

Medicare, which provides health insurance to Americans over the age of 65 and to Americans living with disabilities, is one of the government's largest social programs. It accounts for 12 percent of federal on- and off-budget outlays, and in fiscal year 1999, $\$ 212$ billion in Medicare benefits were paid. The largest shares of spending are for inpatient hospital services (48 percent) and physician services ( 27 percent). In thirty years, the number of Americans covered by Medicare will nearly double to 77 million, or 22 percent of the U.S. population.

Perhaps the most important question we can ask about the Medicare program is, What impact does it have on the health of the U.S. population? One feature of the Medicare program can be exploited to shed light on its impacts: its age specificity. Most people become eligible for Medicare suddenly, the day they turn 65 . Consequently, the age profiles of health services utilization and health outcomes (morbidity and mortality) can provide revealing evidence about Medicare's impacts.

My objective is to obtain precise estimates of medical utilization and outcomes, by single year of age, for ages close to age 65 . The most precise estimates can be obtained by using information obtained from medical providers (hospitals and doctors) pooled over several years.

Utilization of ambulatory care and, to a much smaller extent, inpatient care increases suddenly and significantly at age 65 , presumably due to Medicare eligibility. The evidence points to a structural change in the frequency of physician visits precisely at age 65 . Attainment of age 65 marks not only an upward shift but also the beginning of a rapid upward trend (up until age 75) of about 2.8 percent per year in annual visits per capita. The number of physician visits in which at least one drug is prescribed also jumps up at age 65. Reaching age 65 has a strong positive impact on the consumption of hospital services, but most of this impact appears to be the result of postponement of hospitalization in the prior two years.

We also examine whether this increase in utilization leads to an improvement in outcomes-a reduction in morbidity and mortality-relative to what one would expect given the trends in outcomes prior to age 65 . The estimates are consistent with the hypothesis that the Medicare-induced increase in health 
care utilization leads to a reduction in days spent in bed of about 13 percent and to slower growth in the probability of death after age 65 . Physician visits are estimated to have a negative effect on the male death rate, conditional on age and the death rate in the previous year. The short-run elasticity of the death rate with respect to the number of physician visits is -.095 , and the long-run elasticity is -.497: a permanent or sustained 10 percent increase in the number of visits ultimately leads to a 5 percent reduction in the death rate.

Data on age-specific death probabilities every 10 years since 1900 , i.e., before as well as after Medicare was enacted, provide an alternative way to test for the effect of Medicare on longevity. They also provide strong support for the hypothesis that Medicare increased the survival rate of the elderly by about 13 percent.

\section{Introduction}

Between 1965 and 1967, there was a huge (65 percent) increase in real per-capita public health expenditure (figure 2.1). Medicare, which today provides health insurance to Americans over the age of 65, accounted for more than half (57 percent) of the 1965-1967 increase in public health expenditure.

Figure 2.2 reveals that this increase in public health expenditure was offset, to some extent, by a reduction in private health expenditure. I estimate that each additional dollar of public health expenditure "crowded out" about 43 cents of private spending. ${ }^{1}$ Nevertheless, enactment of Medicare and Medicaid led to significant increases in per-capita health expenditure.

Perhaps the most important question we can ask about the Medicare program is, What impact has it had on the health of the U.S. population? Attempting to answer this question with either individual-level or aggregate data may be fraught with difficulties.

At the individual level, there is often an inverse relationship between medical expenditures and health outcomes: people in poor health have higher medical expenditures. The expenditures may improve their health, but unless a person's health is observable both pre- and postexpenditure-which is usually not the case-the contribution of expenditure to health cannot be identified.

The Health Care Financing Administration (2000) cites aggregate data to support its argument that "the average life expectancy of elderly Americans has increased, in part, because of Medicare." That claim seems plausible. Life expectancy at age 65 increased at a faster rate since Medicare than it did before Medicare: 2.0 years between 1970 


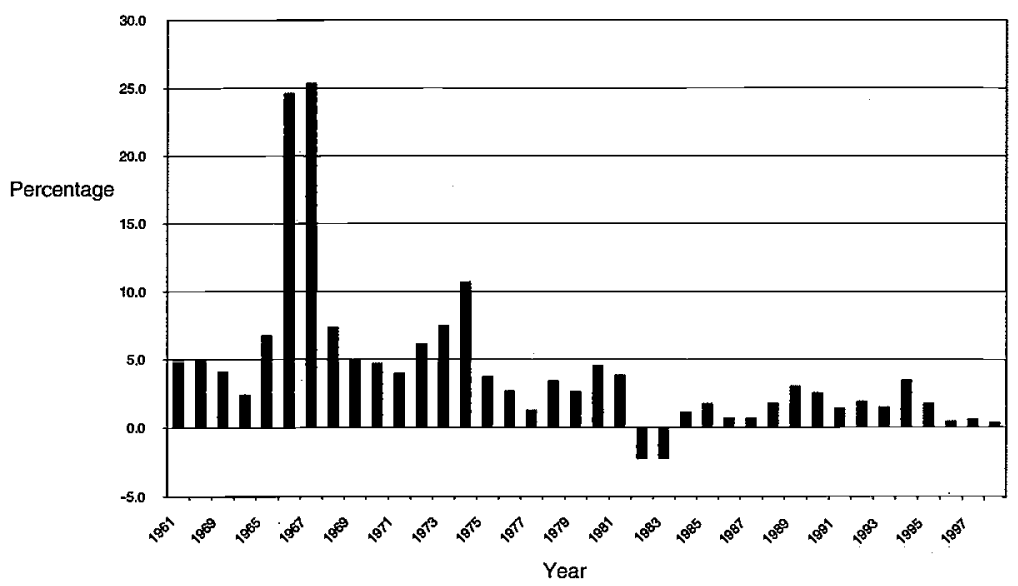

Figure 2.1

Percentage increase from previous year in real per-capita public health expenditure

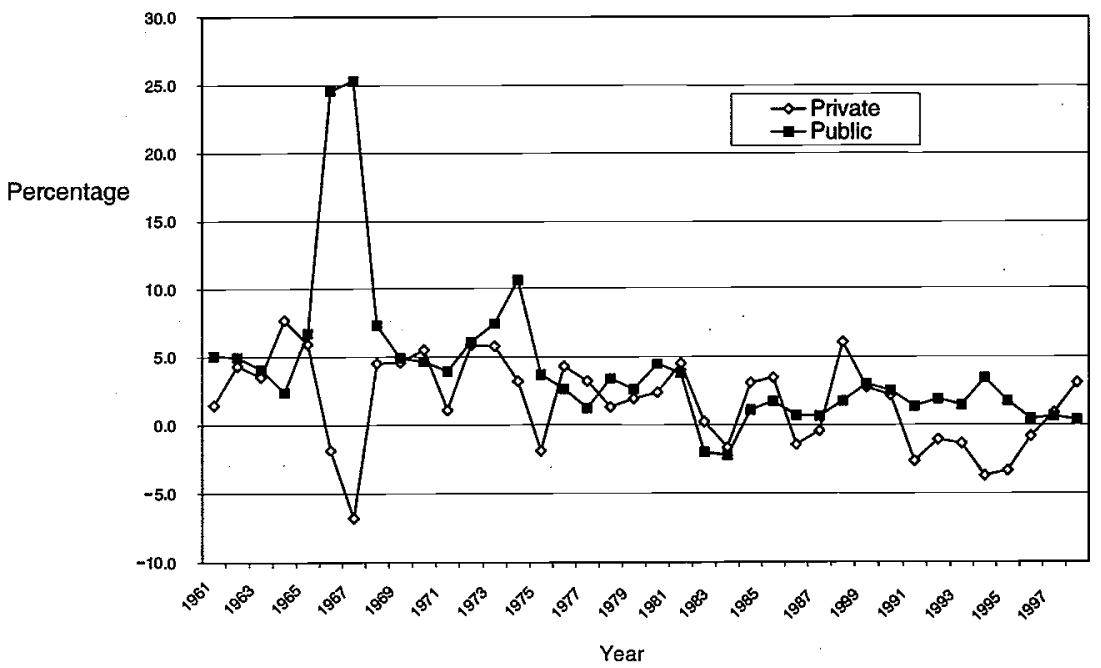

Figure 2.2

Percentage increase from previous year in real per-capita public and private health expenditure 
and 1990 versus 1.3 years between 1950 and 1970, although data on life expectancy at age 65 , by gender, reveal that only men experienced faster growth in life expectancy after Medicare than before Medicare (see figure 2.3). Other factors, such as changes in rates of public and private biomedical innovation and government income security programs, may also have contributed to the acceleration of life expectancy at age 65, making it difficult to isolate the contribution of Medicare from aggregate time-series data.

One feature of the Medicare program can be exploited to shed light on its impacts: its age specificity. Most people become eligible for Medicare suddenly, the day they turn 65 . Consequently, the age profiles of health services utilization and health outcomes (morbidity and mortality) can provide revealing evidence about Medicare's impacts.

\section{Changes in Utilization and Outcomes at Age 65}

Most Americans become eligible for Medicare benefits upon reaching the age of 65. (In 1990, 90 percent of Medicare beneficiaries were elderly, as opposed to disabled or ESRD enrollees.) Consequently, comparisons of health utilization and outcomes just before and just after age 65 may shed light on the impact of Medicare. Some variables (for example, mortality rates) may exhibit a trend prior to age 65 . In such cases, it is appropriate to examine whether there is a break in the trend at age 65 , rather than to test for a pre- versus post- 65 difference in levels.

Medicare eligibility is not the only major event that many people experience at or around the age of 65 . Another important event is retirement. Indeed, the intent of Medicare was evidently to ensure that people continued to have access to medical care after they retired and were no longer covered by employer-sponsored health insurance.

From this perspective, if Medicare had accomplished its objectives exactly, one might expect to observe no difference between (or no shift in the trend in) utilization and outcomes pre- versus post-age 65. Suppose that, in the absence of Medicare, a person's medical expenditure would drop significantly upon retirement, assumed to occur at age 65 . The objective of Medicare was simply to fill the gap left by the termination of employer-sponsored insurance. This scenario is depicted in figure 2.4. 


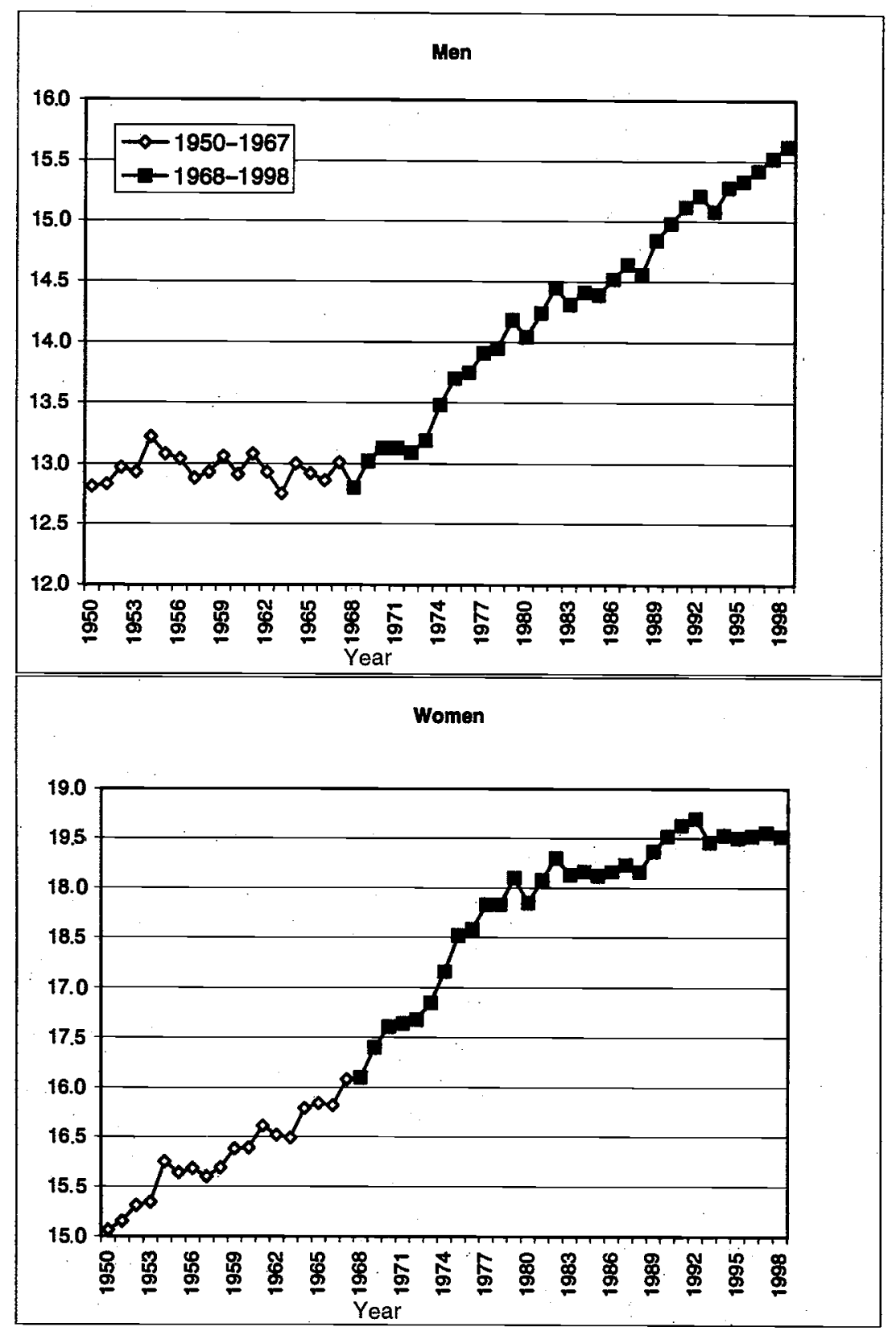

Figure 2.3

Life expectancy at age 65, 1950-1998, by gender 


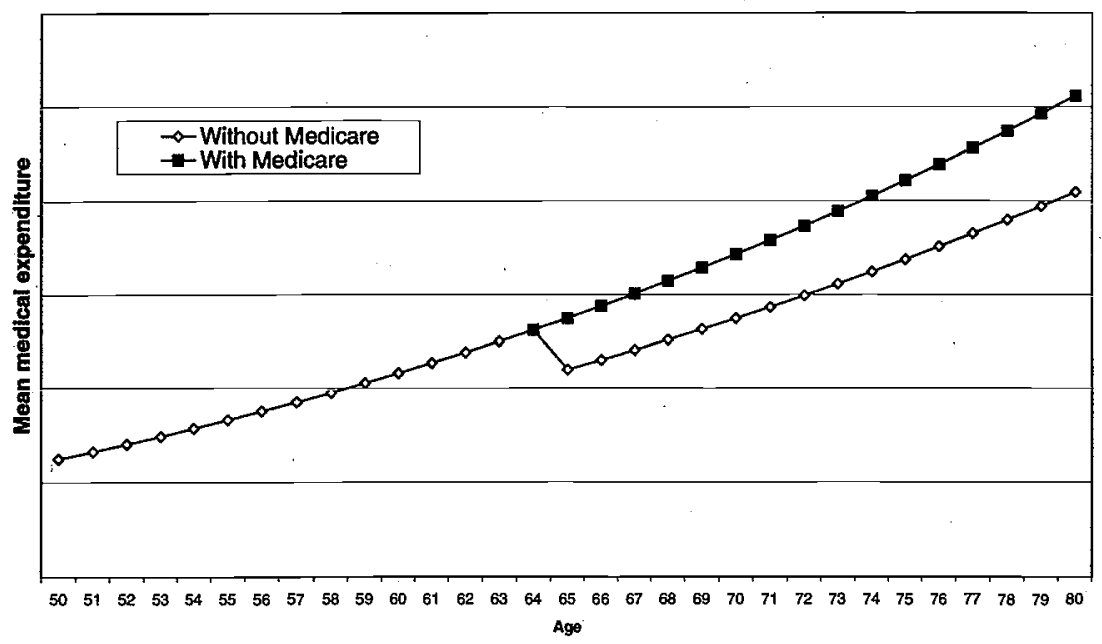

Figure 2.4

Hypothetical effect of Medicare on age/medical expenditure profile

Presumably, policy makers did not intend to induce an upward shift in the age-expenditure profile at age 65 . If they believed that medical expenditure before age 65 was too low, they could have designed the program to provide at least some benefits to people younger than 65 . If policy makers wanted people to consume about the same amount of medical services (for example, physician visits) at age 66 as they had done at age 64, they should have ensured that the out-of-pocket cost was higher at age 66 because the consumption of medical services requires two inputs: purchased medical services (for example, the physician's time) and the patient's time. The opportunity cost (foregone earnings) of the patient's time is much higher before than after retirement. Therefore, if out-of-pocket cost is the same, one would expect people to visit the doctor more after they have retired.

If everyone retired at age 65, when they become eligible for Medicare, it would be almost impossible to distinguish between the effects of retirement and the effects of Medicare from the age profiles of utilization and outcomes. In practice, however, many people retire before reaching the age of Medicare eligibility. According to Social Security Administration data for December 2000, 46 percent of workers retire by age $62,{ }^{2}$ and 62 percent of workers retire by age 64 . Hence, if there are abrupt changes in utilization and outcomes precisely at age 65 , it is unlikely that they can be accounted for by retirement. 


\section{The Age-Utilization Profile}

My objective is to obtain precise estimates of medical utilization and outcomes, by single year of age, for ages close to age 65 . Household surveys, such as the 1996 Medical Expenditure Panel Survey (MEPS) and its predecessors, contain comprehensive information, but the number of individuals of any given age is quite small, resulting in large sampling error. For example, the average number of people per single year of age is only 221 for ages 45-64 in MEPS. Much more precise estimates can be obtained by using information obtained from medical providers (hospitals and doctors) pooled over several years.

\section{Hospital Discharges}

I obtained data on hospital discharges, by age, from the National Hospital Discharge Survey, 1979-1992, Multi-Year Data File. The National Hospital Discharge Survey (NHDS) provides data on inpatient utilization of short-stay, nonfederal hospitals in the United States. The NHDS abstracts both demographic and medical information from the face sheets of the medical records of inpatients selected from a national sample of hospitals. Based on this information, national and regional estimates of characteristics of patients, lengths of stay, diagnoses, and surgical and nonsurgical procedures in hospitals of various bed sizes and types of ownership are produced. The 1979-1992 Multi-Year Data File contains records of about 2.8 million nonnewborn hospital discharges.

The age profile of hospital discharges is shown in figure 2.5 . There is a marked discontinuity in the profile at age 65. The yearly (by age) growth rate of hospital discharges is shown in figure 2.6. From age 50 to age 62 , the number of discharges increases by about 3 percent per year of age. From age 62 to age 64, the number of discharges is essentially constant (it actually declines a little). Between age 64 and age 65, the number of discharges increases 9.5 percent. Between ages 65 and 74 , it increases about 0.5 percent per year.

This evidence indicates that reaching age 65 has a strong positive impact on the consumption of hospital services. However, much of this impact appears to be the result of postponement of hospitalization in the prior two years. The average annual growth rate from age 62 to 65 is 3.1 percent. In contrast, the average annual growth rate from age 50 


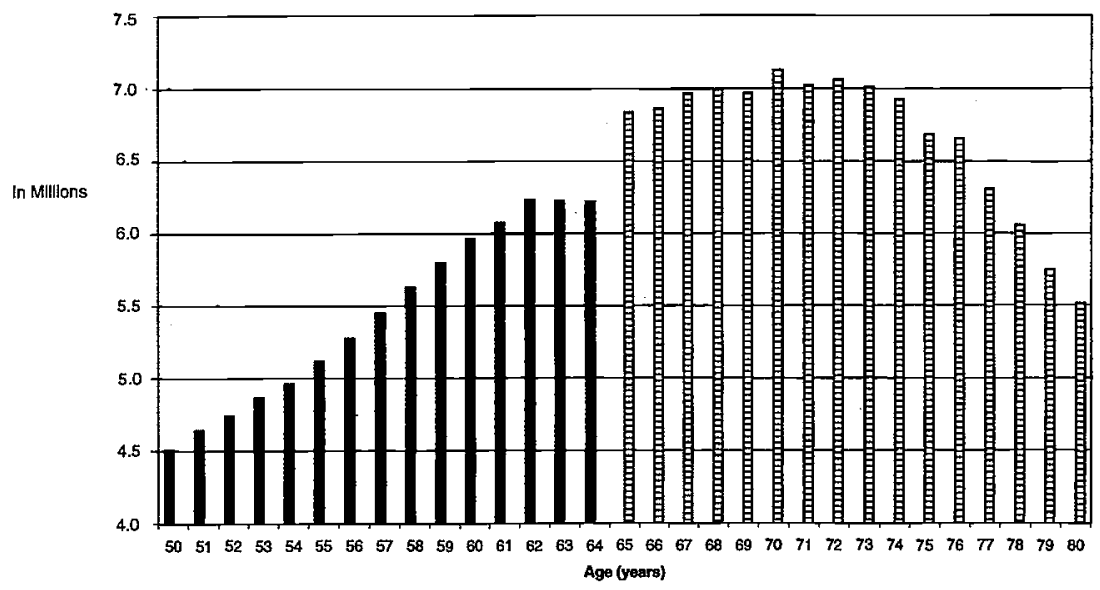

Figure 2.5

Number of 1979-1992 hospital admissions, by single year of age

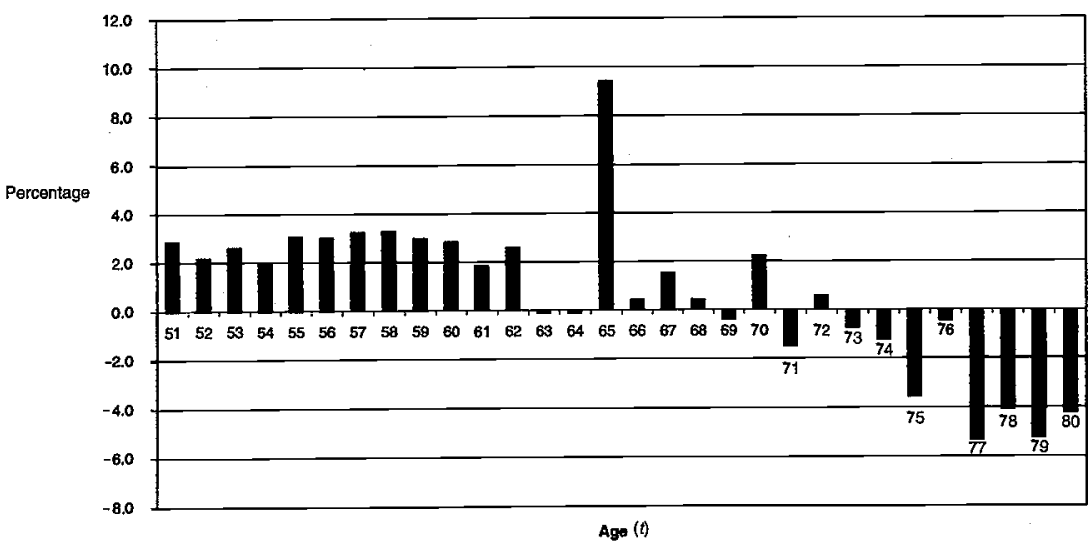

Figure 2.6

Percentage increase in number of hospital admissions from age $t-1$ to age $t$ 
to 62 is 2.3 , and from 59 to 62 is 2.4 percent. Hence the "excess" growth from age 62 to 65 is 0.7 to 0.8 percent per year, or about 2.1 to 2.4 percent additional discharges by the age of 65 .

\section{Physician Visits}

I computed the frequency of physician office visits, by single year of age, by pooling data from the National Ambulatory Medical Care Surveys (NAMCS) for each of the seventeen years during 1973-1998 in which the survey was conducted. ${ }^{3}$ The number of visits surveyed varies from year to year; the 1998 survey contains information from 24,715 patient visits. The pooled data set contains data on approximately 313,000 visits.

Average number of physician office visits, per person per year by single year of age for ages 61-69, are shown in figure 2.7.4 As in the case of hospital discharges, the evidence points to a structural change in visit frequency precisely at age 65 . The average annual number of physician visits is 9.5 percent higher for ages 65-69 than it is for ages 61-64. Once they are eligible for Medicare, people visit the doctor more often. $^{5}$

Figure 2.8 displays data on Medicare and non-Medicare physician visits per person per year, using a wider age window. From age 50 to age 64, the number of annual visits per capita is flat, and even exhibits a tendency to decline from age 58 to age 64 . Attainment of age 65 marks not only an upward shift but also the beginning of a rapid upward trend (up until age 75 ) of about 2.8 percent per year in annual visits per capita.

Since physicians prescribe at least one drug in about two-thirds of office visits, one would expect the number of "drug visits"-visits in which at least one drug is prescribed-also to increase at age 65. Figure 2.9 (based on data for 1985 and 1989-1998) confirms that this is the case. The number of drug visits increases 11.3 percent from age 64 to age 65 . The average annual number of drug visits is 19 percent higher among 65 to 72-year-olds than it is among 60 to 64-year-olds.

Data from the 1996 Medical Expenditure Panel Survey, a household-based survey, also indicate a sharp increase in pharmaceutical use near the age of 65. As shown in figure 2.10, the median number of annual prescriptions (including refills and free samples) increases from 7.3 for people age 56 to 65 to 12.1 for people age 66 to 75 . 


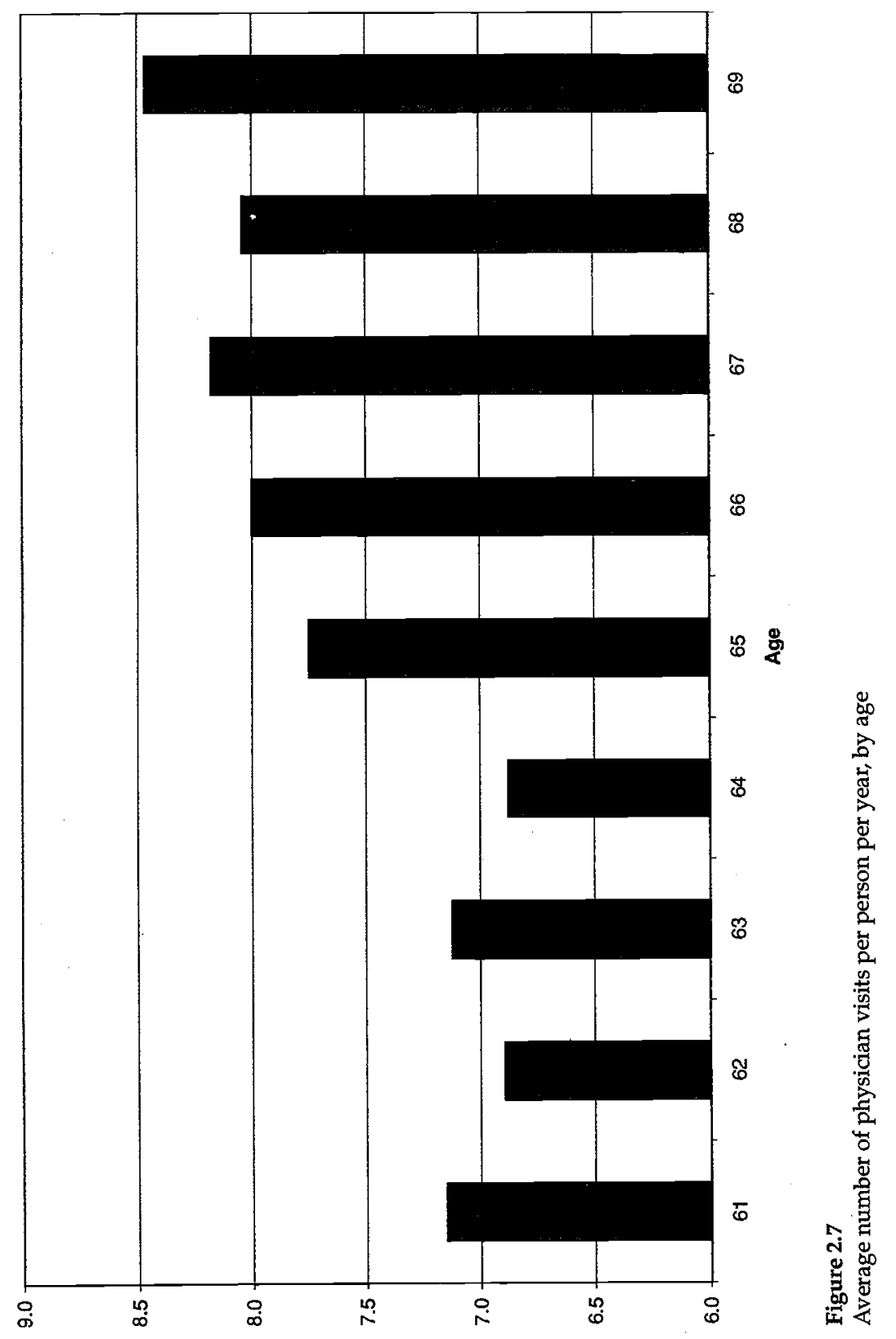




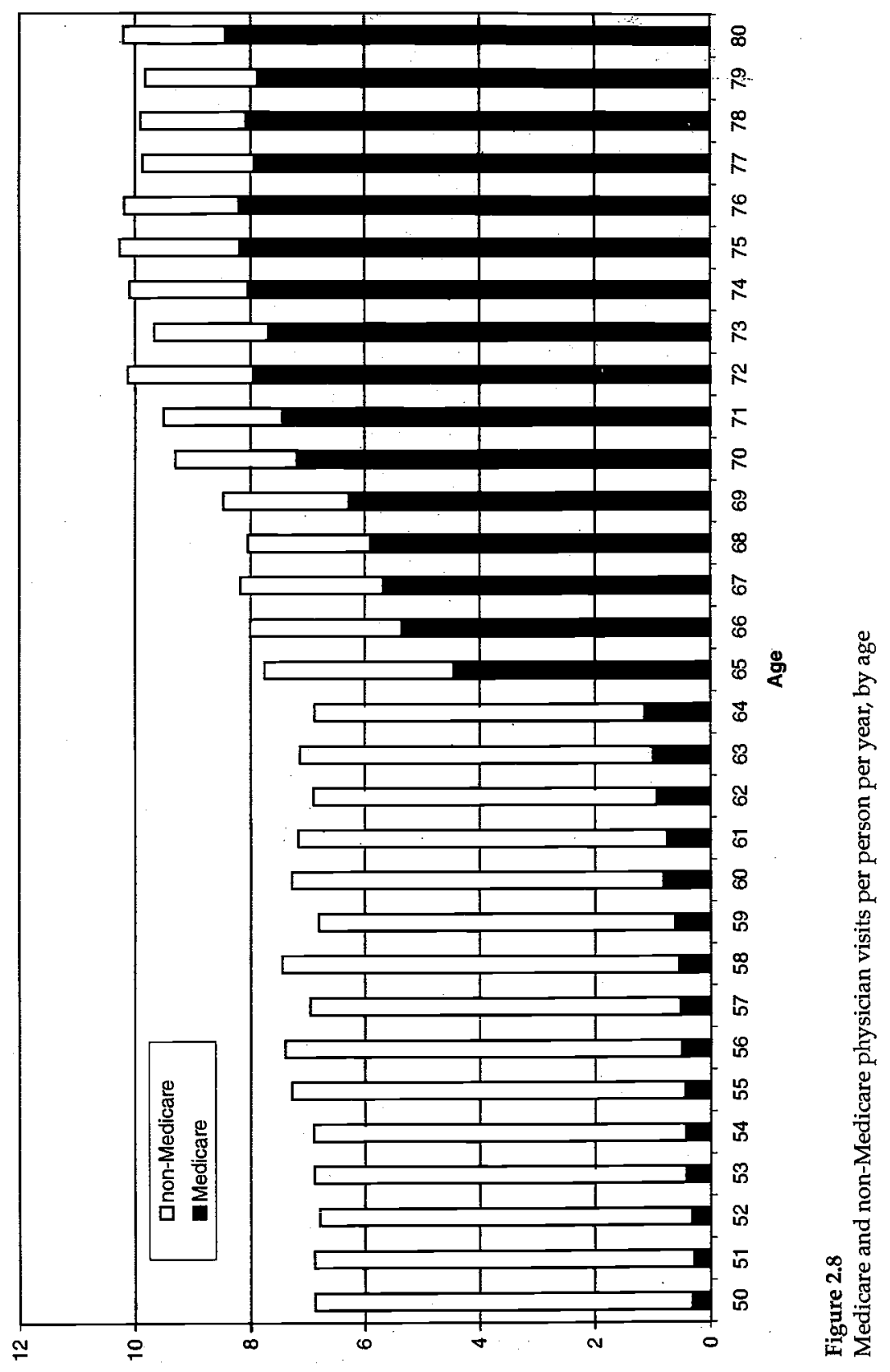




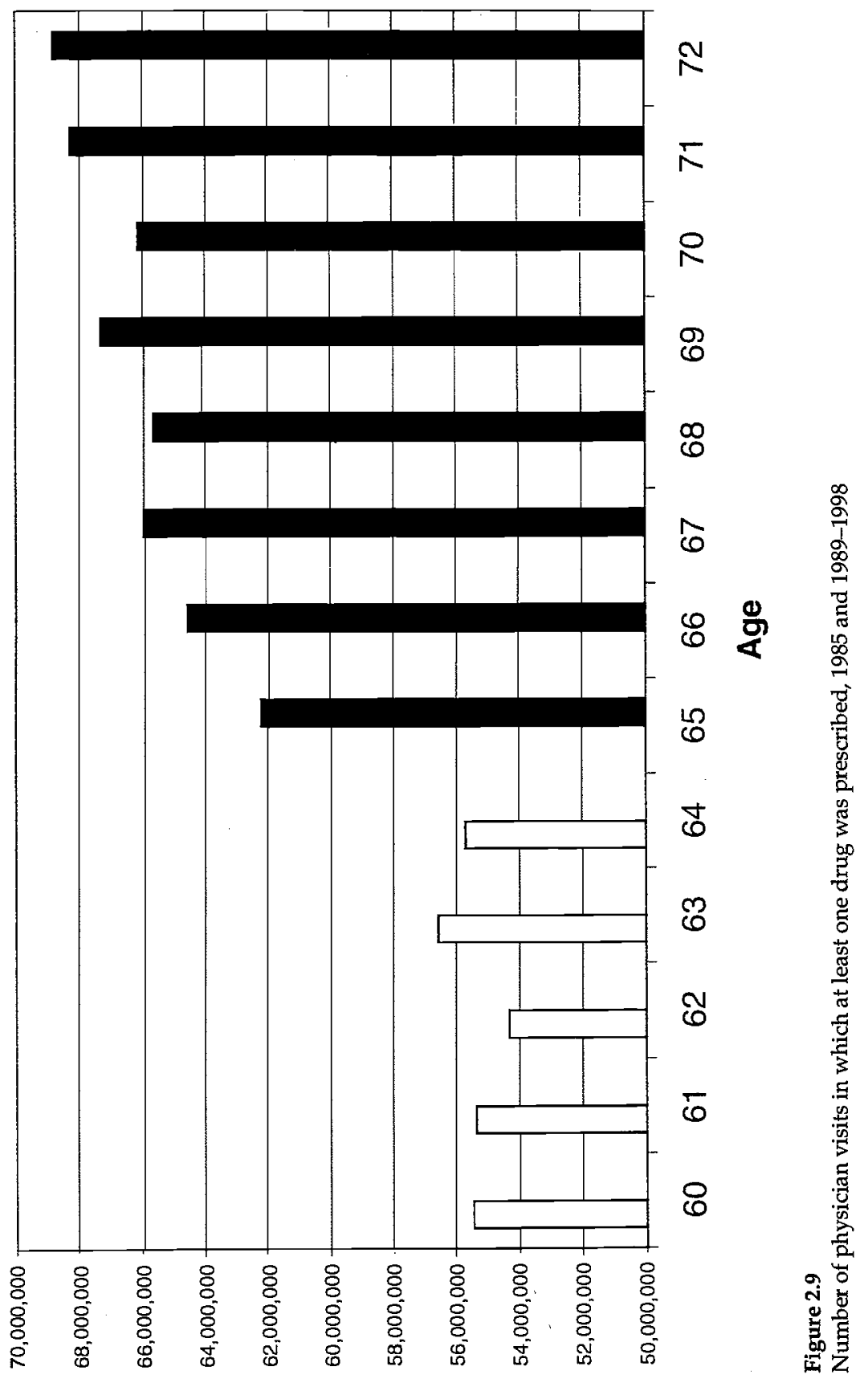




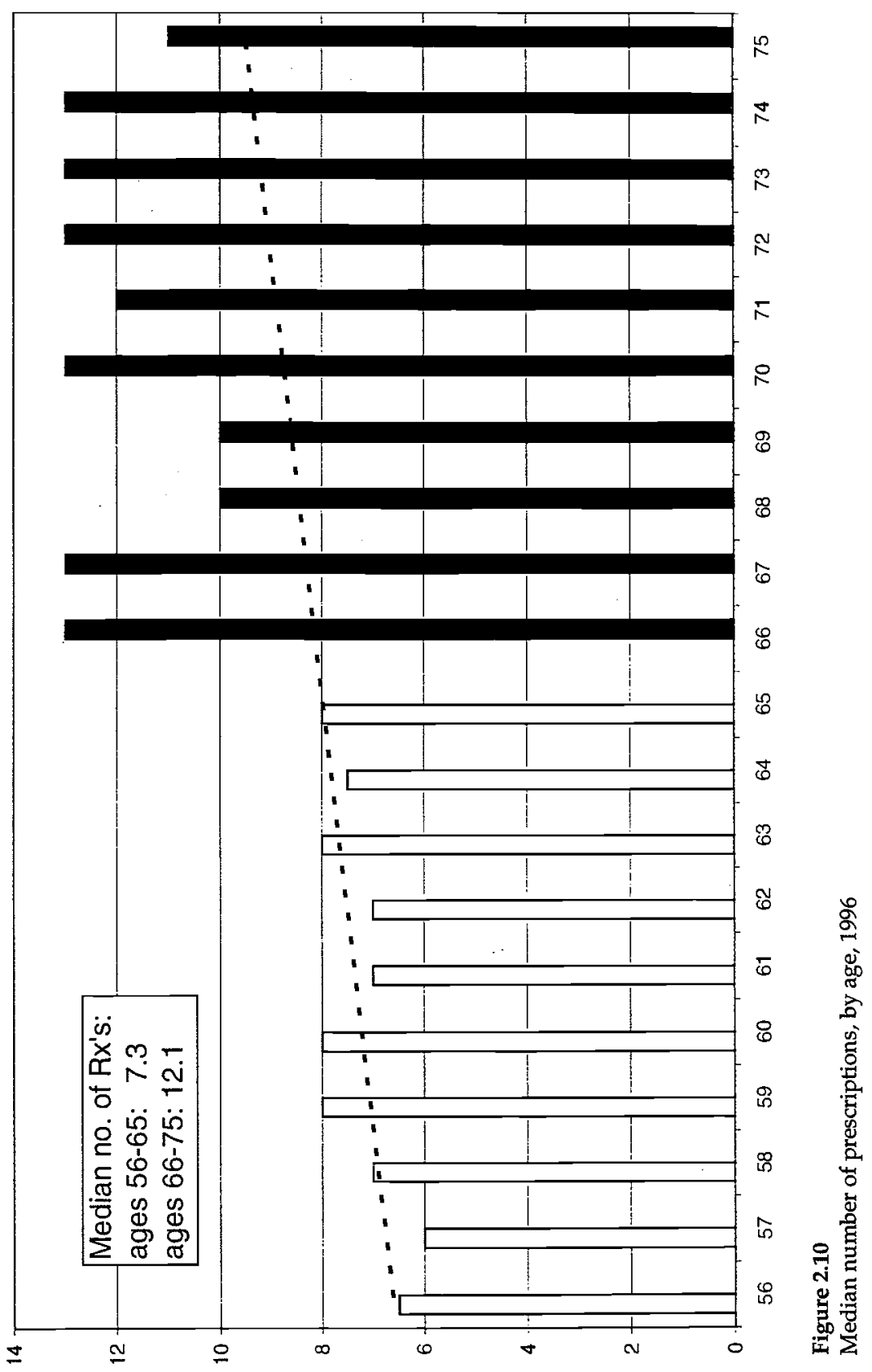




\section{The Age-Outcomes Profile}

The evidence just presented indicates that utilization of ambulatory care and, to a much smaller extent, inpatient care increases suddenly and significantly at age 65, presumably due to Medicare eligibility. We now address the question, Does this increase in utilization lead to an improvement in outcomes-a reduction in morbidity and mortality-relative to what one would expect given the trends in outcomes prior to age 65 ?

\section{Bed Days}

Data on one important indicator of morbidity-mean number of days spent in bed in the last twelve months, by age-are available from the National Health Interview Survey (NHIS). The purpose of the NHIS is to obtain information about the amount and distribution of illnesses, their effect in terms of disability and chronic impairments, and the kinds of health services people receive. I calculated mean annual bed-days from NHIS person files for the five years 1987-1991. These files contain data on about 142,000 people between the ages of 50 and 80 .

Mean annual bed days, by five-year age groups, are shown in figure 2.11. Mean bed days increases by 0.62 from ages $50-54$ to ages $55-59$, and increases even more-by 1.63 days-from ages 55-59 to ages 60-64. However, mean bed days of 65 to 69-year-olds is slightly lower than that of 60 to 64 -year-olds. If the pre-age-65 trend (14 percent average quinquennial growth rate) had continued, mean bed days of 65 to 69-year-olds would have been 15 percent higher-10.58 days as opposed to 9.21 days. Mean bed days of 70 to 74-year-olds and 75 to 80 -year-olds would also have been about 15 percent higher. These estimates are consistent with the hypothesis that the Medicare-induced increase in health care utilization at age 65 leads to a reduction in days spent in bed of about 13 percent.

\section{Mortality}

To examine the shape of the age-mortality profile, I will use data taken from the period life table. There are two types of life tables-the generation or cohort life table and the period life table. The generation life table provides a longitudinal perspective because it follows the mortality 


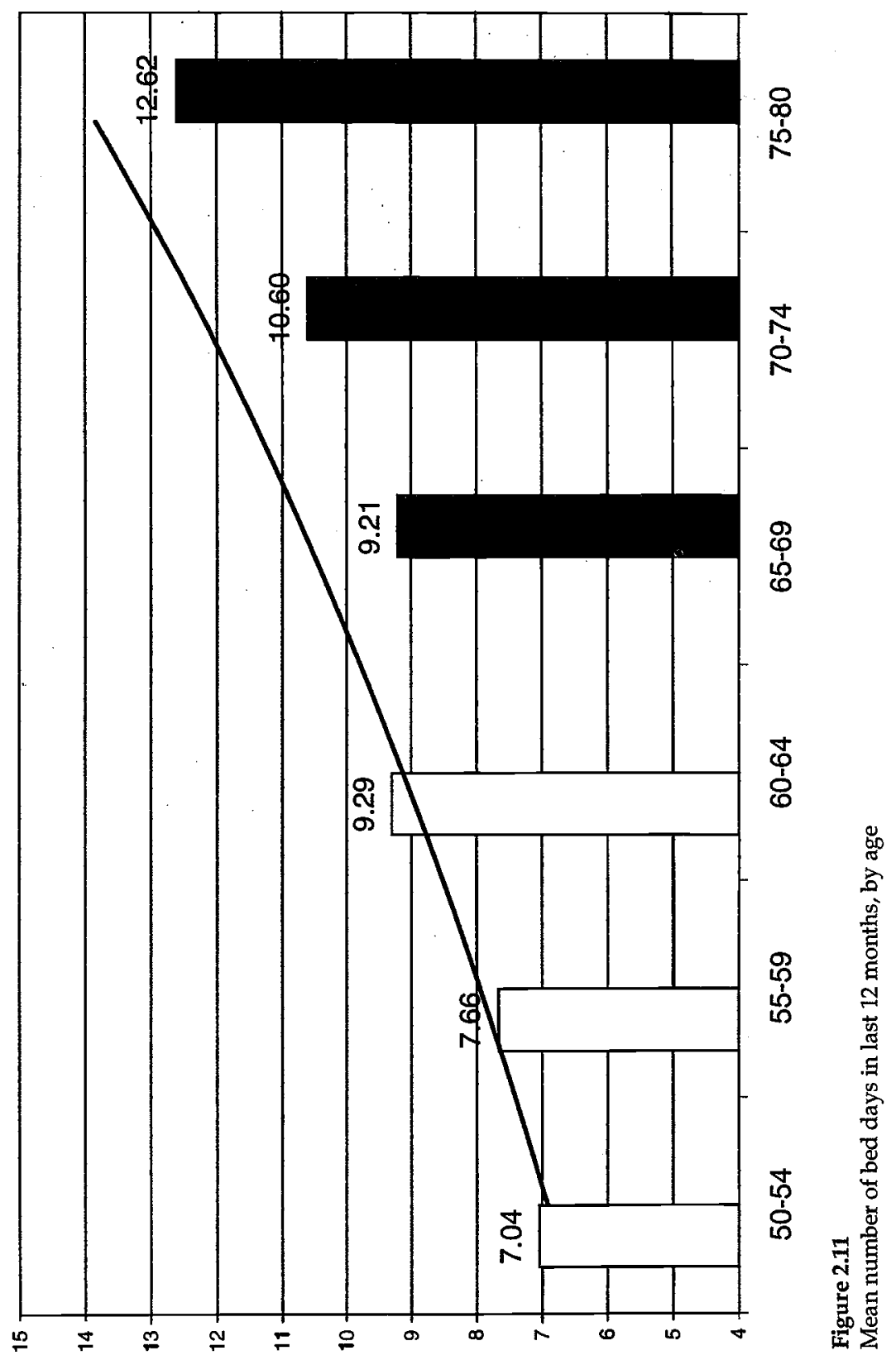


experience of a particular cohort (all persons born in the year 1900, for example) from the moment of birth through consecutive ages in successive calendar years. Based on age-specific death rates observed through consecutive calendar years, the generation life table reflects the mortality experience of an actual cohort from birth until no lives remain in the group. To prepare just a single complete generation life table requires data over many years. It is not feasible to construct generation life tables entirely on the basis of actual data for cohorts born in this century. It is necessary to project data for the incomplete period for cohorts whose life spans are not yet complete.

The better-known period life table may, in contrast, be characterized as cross-sectional. Unlike the generation life table, the current life table does not represent the mortality experience of an actual cohort. Rather, the current life table considers a hypothetical cohort and assumes that it is subject to the age-specific death rates observed for an actual population during a particular period. For example, a current life table for 1995 assumes that a hypothetical cohort is subject throughout its lifetime to the age-specific death rates prevailing for the actual population in 1995. The current life table may thus be characterized as rendering a "snapshot" of current mortality experience, and shows the long-range implications of a set of age-specific death rates that prevailed in a given year.

Period life tables are produced annually by two different federal agencies: the National Center for Health Statistics (NCHS) and the Social Security Administration (SSA), Office of the Actuary. Wilkin (1981) discusses the methods used to construct both sets of life tables and their relative reliability. NCHS tables are based primarily on data obtained from death certificates. Misstatement of the age of the decedent on death certificates is known to be a serious problem. SSA life tables utilize administrative data from the Medicare program. As Wilkin observes, over the years, the Medicare program has accumulated a large quantity of reliable data on the mortality of the aged. The problem of misstatement of age is greatly reduced in this case because most of the data relate to individuals who have had to verify their dates of birth to become entitled to benefits under the program. ${ }^{6}$ The problem of underregistration of deaths is small because the availability of a small lump-sum death payments on insured workers' accounts encourages survivors and funeral directors to report deaths. The problem of underenumeration of population is negligible because the group under observation is defined by program records; thus, the data do not in- 
clude deaths of unobserved persons. Further, the data are so extensive, covering nearly the entire aged population of the United States, that meaningful analyses can be done over relatively short periods of time (and, hence, trends through time can be detected accurately).

Wilkin concludes that "the Medicare data appear to be more accurate by age and more consistent through time than the NCHS data." The trustees of the Social Security system base their projections of income and outlays on SSA life tables rather than NCHS life tables. Therefore I will examine data on age-specific mortality rates from the SSA period life table. In particular, I will use the 1995 SSA period life table.

The table provides data on the probability of dying within one year ("death probability"), by exact age (age $=1,2, \ldots, 119$ ) and gender. Death probabilities of men, by age, are shown in figure 2.12. It seems in this figure that the death probability increases smoothly from about 1 percent at age 55 to about 5 percent at age 75 . However, the appearance of smoothly increasing death probabilities is deceptive. Figure 2.13 depicts the percentage increase in the male death probability from the previous year. From age 50 to age 65, the death probability increases at an increasing rate. Initially, the death rate increases about 8 percent a year, and the growth rate rises fairly steadily to about 10 percent by age 65 . But between ages 65 and 69, the slope of the curve is quite negative. The probability of death continues to increase, but more slowly than it did up until age 65. As figure 2.14 reveals, there is a similar dramatic decline in growth in the probability of the death of women after age 65 .

Suppose that, instead of declining after age 65, the growth rate of the probability of death for men had continued to grow at the rate it had grown from age 50 to age 65 . Then as figure 2.15 indicates, the probability that a 65 -year-old man would live at least 10 more years would have been 63.5 percent, rather than the actual probability of 68.6 percent. The post- 65 slowdown in death probability raised the odds of being able to celebrate one's 75th birthday by 5.1 percentage points. ${ }^{7,8}$

This evidence is consistent with the hypothesis that the Medicareinduced increase in health care utilization at age 65 leads to slower growth in the probability of death after age 65. I performed a formal test of this hypothesis using regression analysis. Using data for ages 51 to 75 , I estimated the following regression equation:

$$
\begin{gathered}
d_{j}=-1.86+.809 d_{j-1}-.095 \text { visits }_{j}+.030 \text { hosp }_{j}+.018 j \\
(t=1.40)
\end{gathered}
$$




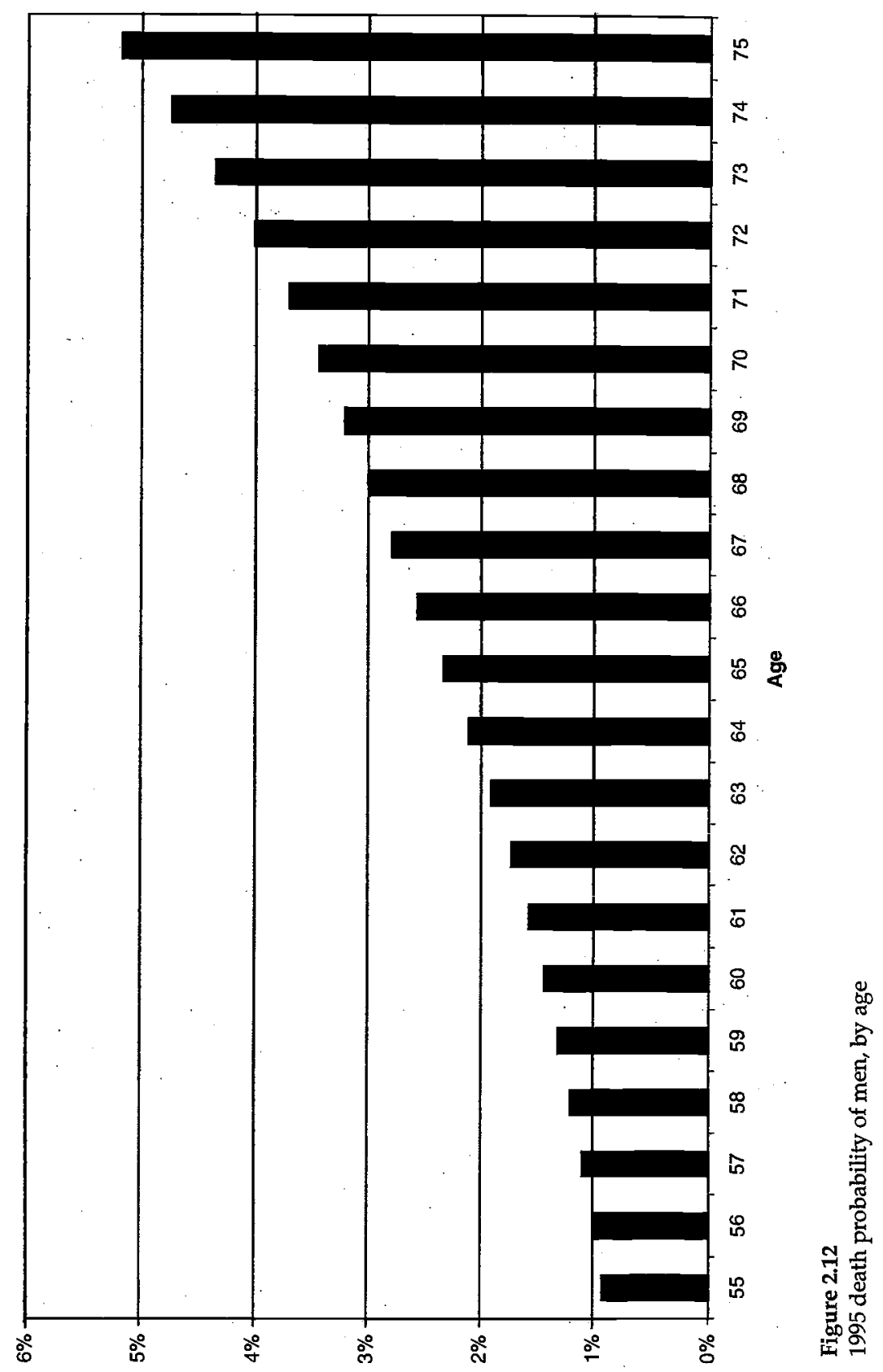




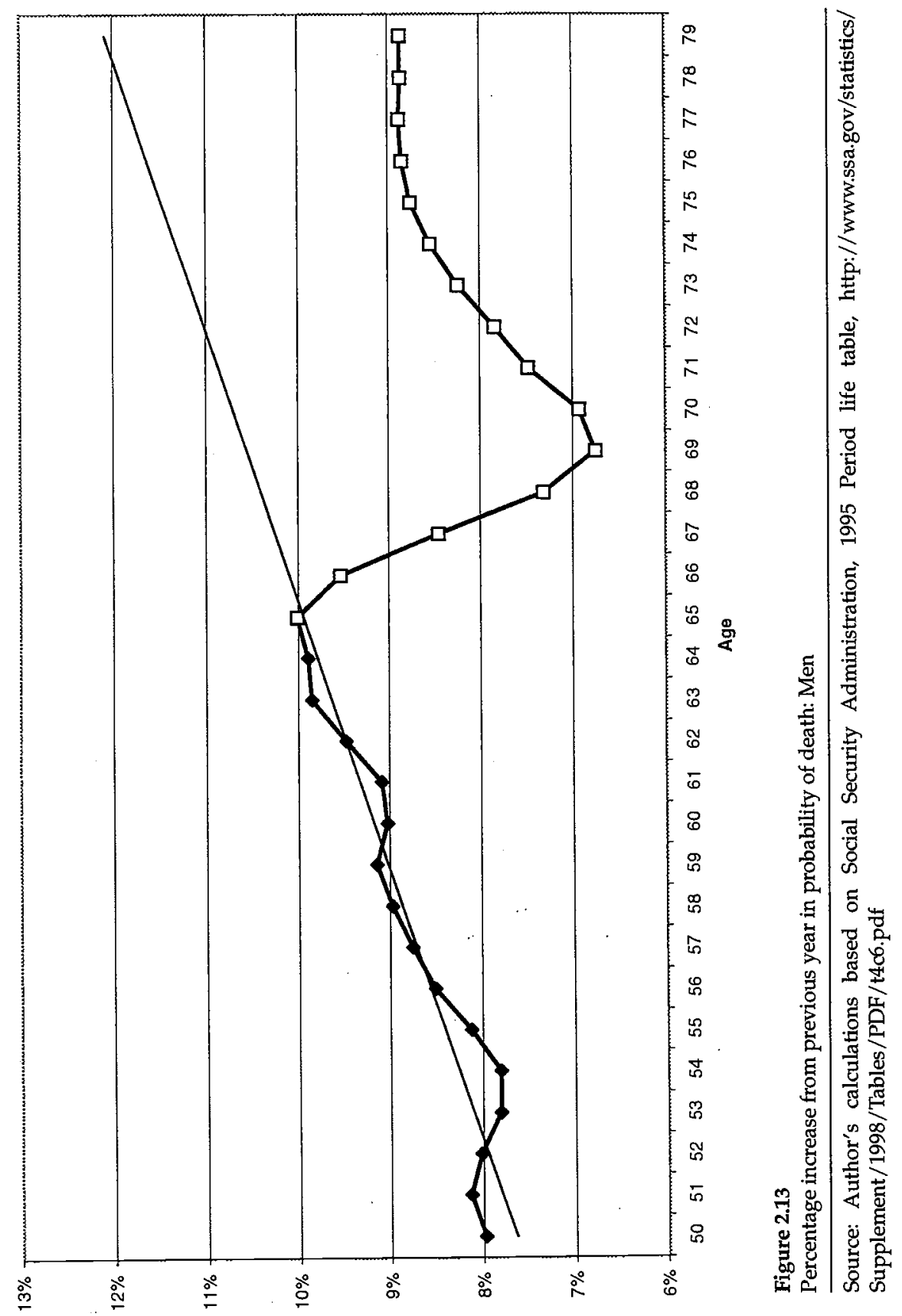




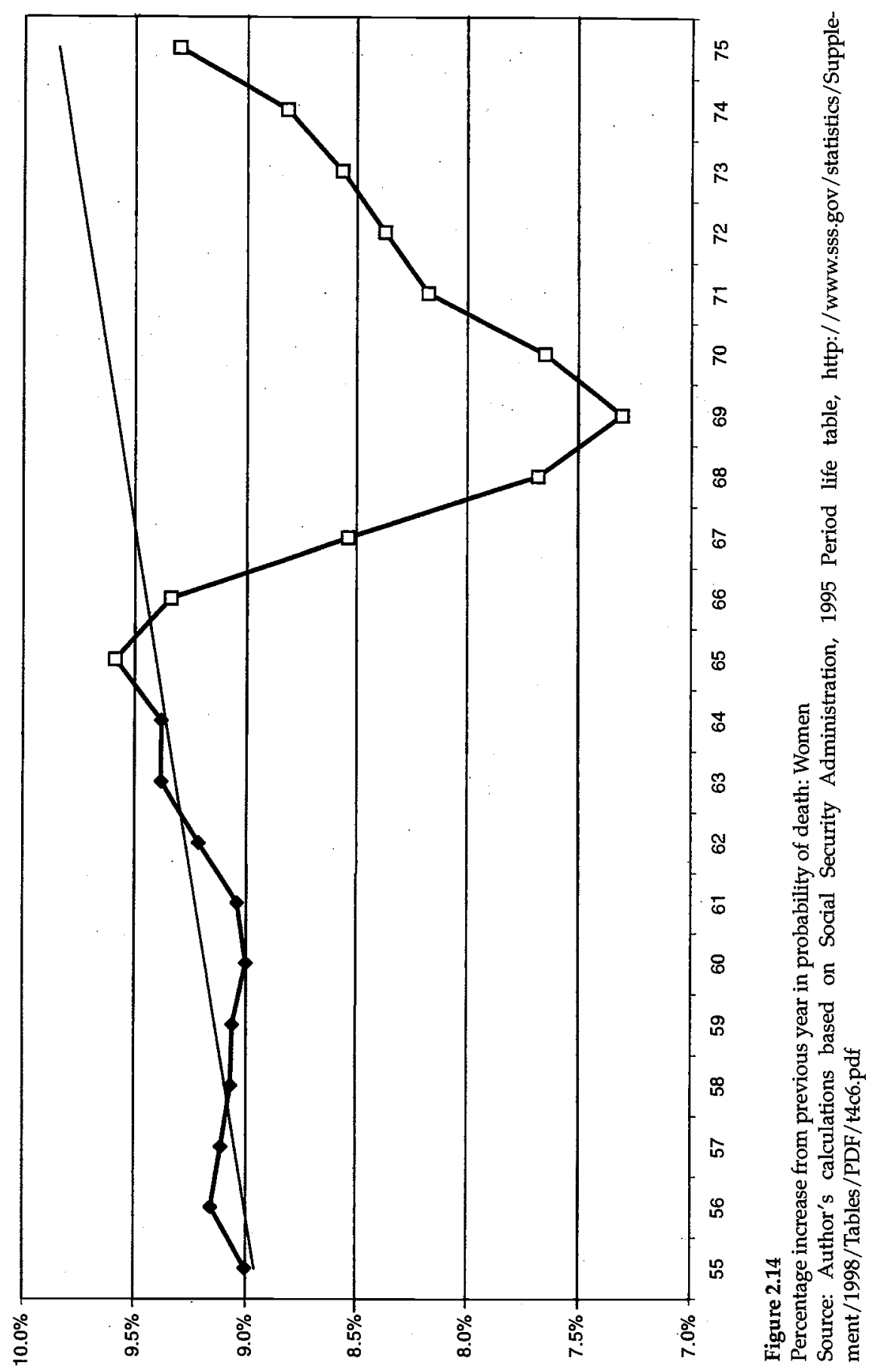




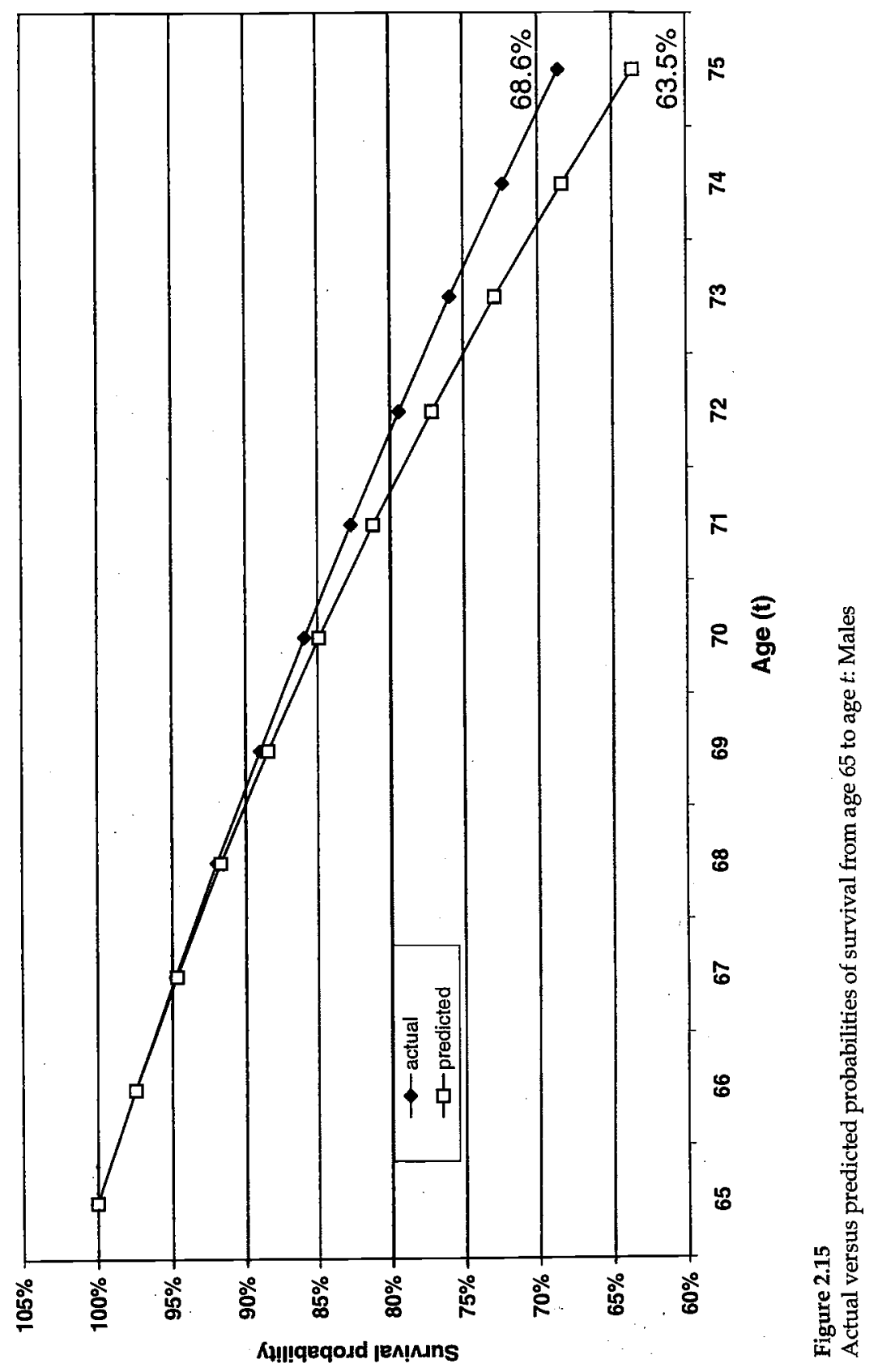


where

$d_{j}=$ the log of the male death rate at age $j$

visits $_{j}=$ the log of the number of physician visits at age $j$

hosp $\mathrm{p}_{j}=$ the log of the number of hospital discharges at age $j$

The hospital coefficient is not statistically significant, but the visits coefficient is highly significant ( $p$ value $=.004$ ), indicating that physician visits have a negative effect on the male death rate, conditional on age and the death rate in the previous year. In the short run, the elasticity of the death rate with respect to the number of physician visits is -.095 ; 10 percent increase in the number of visits leads to an immediate reduction in the death rate of 0.95 percent. In the long run, the elasticity of the death rate with respect to the number of physician visits is $-.497(=-.095 /[1-.809])$ a permanent or sustained 10 percent increase in the number of visits ultimately leads to a 5 percent reduction in the death rate.

\section{Mortality: An Alternative Approach}

The analysis in the previous section was based on age-specific death probabilities in a single year (1995). But data on age-specific death probabilities are available from NCHS (Anderson (1997) every 10 years back to 1900, that is, before as well as after Medicare was enacted. Medicare, which began in 1966, primarily benefits people age 65 and over. ${ }^{9}$ Hence 70 -year-olds in 1970 and 1980 benefited from the program, but 70-year-olds in 1960 did not, nor did 60-year-olds in any year. An alternative way to test for the effect of Medicare on longevity is to estimate models of the following form:

$\ln S_{i t}=\alpha_{i}+\delta_{i} t+\beta$ shift $+u_{i t}$

where $S_{i t}=$ the survival rate of age group $i$ in year $t(i=1,5,10,15, \ldots$, $100 ; t=1900,1910, \ldots, 1990,1997)$ and "shift" is defined in various ways to test for shifts in survival rates..$^{10}$ This model allows for both a different mean survival rate and a different trend rate of increase for each of the twenty-one age groups. If Medicare resulted in an upward shift of the survival of people over 65 after 1966, then the appropriate definition of the shift variable is:

shift $=1$ if year $>1966$ and age $>65$

$=0$ otherwise 
When shift is defined in this way, the point estimate ( $t$ statistic) of $\beta$ is 0.132 (8.28). This provides strong support for the hypothesis that Medicare increased the survival rate of the elderly, by about 13 percent.

To ensure that this shift corresponds to Medicare as opposed to some other factor(s), we can change the definition of the shift term; that is, we can choose an earlier or later year or a different age. The results of this sensitivity analysis are shown in table 2.1. Lines 2 and 3 indicate that there is no evidence of a shift in the survival rate of people over 65 before 1966 (in either 1950 or 1960). There is stronger evidence of a shift in 1970 than there is of one in 1980 (line 4). Line 5 shows that there is no evidence of a shift in the survival rate of people between the ages of 40 and 65 after 1966. (Although the survival rates of people in this age group increased, there was no shift in the time trend after 1966, as there was for older people.)

\section{Summary}

Medicare, which provides health insurance to Americans over the age of 65 and to Americans living with disabilities, is one of the government's largest social programs. It accounts for 12 percent of federal onand off-budget outlays. In fiscal year 1999, \$212 billion in Medicare benefits were paid. The largest shares of spending are for inpatient hospital services ( 48 percent) and physician services ( 27 percent). In thirty years, the number of Americans covered by Medicare will nearly double to 77 million, or 22 percent of the U.S. population.

Perhaps the most important question we can ask about the Medicare program is, What impact does it have on the health of the U.S. population? One feature of the Medicare program can be exploited to shed light on its impacts: its age specificity. Most people become eligible for Medicare suddenly, the day they turn 65 . Consequently, the age profiles of health services utilization and health outcomes (morbidity and mortality) can provide revealing evidence about the effects of Medicare.

I have attempted to obtain precise estimates of medical utilization and outcomes, by single year of age, for ages close to age 65 . The most precise estimates can be obtained by using information obtained from medical providers (hospitals and doctors) pooled over several years.

I found that the utilization of ambulatory care and, to a much smaller extent, inpatient care increases suddenly and significantly at age 65 , presumably due to Medicare eligibility. The evidence points to a 
Table 2.1

Estimates of equation (2.1) with alternative definitions of shift variable ( $t$ statistics in parentheses)

\begin{tabular}{llcc}
\hline Line & Age criterion & Year criterion & $\beta$ \\
\hline 1 & Age $>65$ & Year $\geq 1970$ & 0.132 \\
& & & $(8.28)$ \\
2 & Age $>65$ & Year $\geq 1950$ & 0.018 \\
& & & $(0.91)$ \\
3 & Age $>65$ & Year $\geq 1960$ & 0.013 \\
& & & $(0.66)$ \\
4 & Age $>65$ & Year $\geq 1980$ & 0.102 \\
& & & $(6.57)$ \\
5 & $40<$ Age $\leq 65$ & Year $\geq 1970$ & 0.004 \\
& & & $(0.2)$ \\
\hline
\end{tabular}

structural change in the frequency of physician visits precisely at age 65. Attainment of age 65 marks not only an upward shift but also the beginning of a rapid upward trend (up until age 75 ) of about 2.8 percent per year in annual visits per capita. The number of physician visits in which at least one drug is prescribed also increases at age 65 . Reaching age 65 has a strong positive impact on the consumption of hospital services, but most of this impact appears to be the result of postponement of hospitalization in the prior two years.

I also examined whether this increase in utilization leads to an improvement in outcomes-a reduction in morbidity and mortality-relative to what one would expect given the trends in outcomes prior to age 65 . The estimates were consistent with the hypothesis that the Medicare-induced increase in health care utilization leads to a reduction in days spent in bed of about 13 percent and to slower growth in the probability of death after age 65 . Physician visits are estimated to have a negative effect on the male death rate, conditional on age and the death rate in the previous year. The short-run elasticity of the death rate with respect to the number of physician visits is -.095 , and the long-run elasticity is -.497; a permanent or sustained 10 percent increase in the number of visits ultimately leads to a 5 percent reduction in the death rate.

Data on age-specific death probabilities every 10 years since 1900, that is, before as well as after Medicare was enacted, provide an alternative way to test for the effect of Medicare on longevity. They also provide strong support for the hypothesis that Medicare increased the survival rate of the elderly, by about 13 percent. 


\section{Notes}

1. I calculated this by estimating the following regression:

$$
\begin{array}{cc}
\Delta \ln \left(\operatorname{Priv}_{t}\right)=3.92 & -0.319 \Delta \ln \left(\mathrm{Pub}_{t}\right)-.0020_{t} \\
(t=4.24) & (3.45)
\end{array}
$$

Adjusted $R^{2}=0.327$

Sample period: 1961-1998

$\operatorname{Priv}_{t}=$ real private health expenditure

$\mathrm{Pub}_{t}=$ real public health expenditure

$\frac{\Delta \text { Priv }}{\Delta \text { Pub }}=-0.319 \frac{\text { Priv }^{\prime}}{\mathrm{Pub}^{\prime}}=-.433$

Priv $^{\prime}=$ mean real private health expenditure

$\mathrm{Pub}^{\prime}=$ mean real public health expenditure

2. The monthly Social Security benefit is about 25 percent lower if one retires at age 62 than it is if one retires at age 65 . As a general rule, early retirement will give one about the same total Social Security benefits over one's lifetime, but in smaller amounts to take into account the longer period during which they will be received.

3. NAMCS was not conducted in 1974, 1982-1984, and 1986-1988.

4. A Medicare visit is defined as a visit in which Medicare is the expected principal source of payment.

5. In 1998, the elderly accounted for 23.8 percent of physician office visits. Medicare was the expected primary source of payment for 19.2 percent of physician office visits.

6. Proof of date of birth requires the submission of a public record of birth or a religious record of birth or baptism. Where no such document is available, the individual must submit another document or documents that may serve as the basis for a determination of his or her date of birth, provided that such evidence is corroborated by other evidence or by information in the records of the Social Security Administration.

7. The corresponding increase for women is only about one-third as large because women's death probabilities at given ages are significantly lower than are men's.

8. In principle, one could calculate the effect of the decline in mortality growth rate on life expectancy at age 65, which is perhaps the most interesting summary statistic. However, this requires predicting counterfactual mortality rates at advanced ages, a potentially speculative undertaking.

9. When it was introduced, 100 percent of Medicare beneficiaries were elderly; today about 14 percent of them are nonelderly disabled:

10. The survival rate is 1 - the death rate. Here, the survival rate is defined as the 5 -year rate, for example, the probability of surviving from age 65 to 70 . 


\section{References}

Anderson, R. N. (1999). United States Life Tables, 1997. National Vital Statistics Reports, Vol. 47, No. 28. Hyattsville, MD: National Center for Health Statistics.

Health Care Financing Administration (2000). Medicare 2000: 35 Years of Improving Americans' Health and Security, July.

Wilkin, John C. (1981). "Recent Trends in the Mortality of the Aged," Transactions of the Society of Actuaries, Vol. XXXIII, 11-62. 